\title{
(2) OPEN ACCESS \\ Sex, military occupation and rank are associated with risk of anterior cruciate ligament injury in tactical- athletes
}

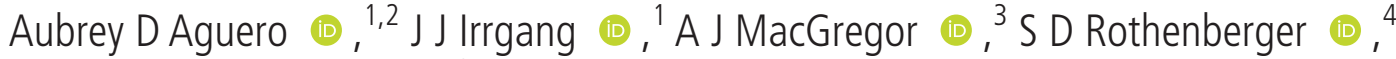 \\ J M Hart (10, ${ }^{5}$ J J Fraser (10 ${ }^{3}$
}

- Additional supplemental material is published online only. To view, please visit the journal online (http://dx.doi. org/10.1136/bmjmilitary-2021002059).

${ }^{1}$ Physical Therapy Department, School of Health \&

Rehabilitation Sciences, University of Pittsburgh,

Pittsburgh, Pennsylvania, USA

${ }^{2}$ Naval Medical Leader \&

Professional Development Command, US Navy Bureau of Medicine and Surgery, Falls Church, Virginia, USA

${ }^{3}$ Operational Readiness \& Health Directorate, Naval Health Research Center, San Diego,

California, USA

${ }^{4}$ Department of Medicine,

University of Pittsburgh School of Medicine, Pittsburgh,

Pennsylvania, USA

${ }^{5}$ Department of Orthopaedic

Surgery, University of

Virginia School of Medicine,

Charlottesville, Virginia, USA

Correspondence to Dr J J Fraser, Operational Readiness \& Health Directorate, Naval Health Research Center, San Diego, CA 92106-3521, USA; john.j.jraser8.mil@mail.mil

Received 4 December 2021 Accepted 16 January 2022

Check for updates

(C) Author(s) (or their employer(s)) 2022. Re-use permitted under CC BY-NC. No commercial re-use. See rights and permissions. Published by BMJ.

\begin{tabular}{l}
\hline To cite: Aguero AD, \\
Irrgang JJ, MacGregor AJ, \\
et al. BMJ Mil Health Epub \\
ahead of print: [please \\
include Day Month Year]. \\
doi:10.1136/ \\
bmjmilitary-2021-002059
\end{tabular}

\section{ABSTRACT}

Introduction Anterior cruciate ligament $(A C L)$ injury is common within the US military and represents a significant loss to readiness. Since recent changes to operational tempo, there has not been an analysis of $\mathrm{ACL}$ injury risk. The aim of this retrospective cohort study was to evaluate military occupation, sex, rank and branch of service on ACL injury risk in the US military from 2006 to 2018.

Methods The Defense Medical Epidemiology Database was queried for the number of US tactical athletes with International Classification of Diseases diagnosis codes 717.83 (old disruption of $A C L$ ), 844.2 (sprain of knee cruciate ligament), M23.61 (other spontaneous disruption of $A C L$ ) and $S 83.51$ (sprain of ACL of knee) on their initial encounter. Relative risk and $\chi^{2}$ statistics were calculated to assess sex and military occupation effects on $\mathrm{ACL}$ injury. A multivariable negative binomial regression model evaluated changes in $A C L$ injury incidence with respect to sex, branch of service and rank.

Results The study period displayed a significant decrease in the ACL injury rate at 0.18 cases per 1000 person-years or relative decrease of $4.08 \%$ each year $(p<0.001)$ after averaging over the main and interactive effects of sex, rank and branch of service. The interaction effect of time with sex indicated a steeper decline in the incidence in men as compared with women. The risk of $A C L$ injury by sex was modified by rank. The incidence among military personnel varied by occupation.

Conclusion Despite the decline among tactical athletes over time, rates of $A C L$ injury remain much higher than the general US population. Sex, rank, branch of service and military occupation were found to be risk factors for $\mathrm{ACL}$ injury. It is critical for policy makers to understand the salient risk factors for $A C L$ injury to guide proactive measures to prevent injury.

\section{INTRODUCTION}

Anterior cruciate ligament (ACL) injury in military members(also referred to as tactical athletes) is estimated to be 10 times that of the civilian population, ${ }^{12}$ which is comparable to the rate of injury in professional or elite athletes. ${ }^{3}$ Previous epidemiological studies of ACL injury in the military population have focused on specific communities such as the US Naval Special Warfare community ${ }^{4}$ and midshipmen at the US Naval Academy $^{5}$; however, these groups are highly active and not representative of the typical military member. In the first military-wide population study assessing ACL injury, Owens et $a l^{1}$ reported the incidence in the US military was 6.6 per 1000 person-years from 1993 to

\section{Key messages}

- Anterior cruciate ligament (ACL) injury is a known command readiness issue in the military, and there is recent evidence of this within subpopulations of the military.

- Sex, rank, branch of service and military occupation have been found to be risk factors for ACL injury.

- There was a $4.08 \%$ decrease in the incidence of ACL injuries between the years 2006 and 2018.

- The rate of decrease was higher in men when considering rank and branch of service.

- The relationship of $\mathrm{ACL}$ injury incidence and sex was modified by rank.

- It is critical for policy makers to understand the salient risk factors for $\mathrm{ACL}$ injury to guide appropriate prophylactic measures to prevent injury.

\section{Questions for future research}

- Does integration of military rehabilitation specialists into patient-centred medical homes and operational units affect anterior cruciate ligament $(A C L)$ injury risk, rehabilitation volume and return to duty rates?

- Does integration of female tactical athletes in combat arms affect ACL injury incidence?

- What are the granular modifiable and nonmodifiable intrinisic risk factors that mediate ACL injury outcomes in military tactical athlete?

2003. The burden of these injuries threaten command readiness, ${ }^{6}$ especially during periods of increased operational requirements. Since the end of the study period investigated by Owens $e t a l^{1}$ coincided with the beginning of the conflicts Operation Enduring Freedom (OEF) in 2001 and Operation Iraqi Freedom (OIF) in 2003, an updated estimate of ACL injury incidence in the US military is needed.

Each service branch comprises an array of diverse military occupations, each of which have unique physical requirements and hazards that may influence injury rates. An overview of military occupational specialties can be viewed at https://bitly/MilOcc. Furthermore, rank may also be a factor due to changes in type and amount of exposure to potential hazards 
throughout a military career. While Antosh $e t a l^{7}$ investigated rank as a factor for return to duty after ACL reconstruction, there is a dearth of evidence pertaining to this as a contributing factor to ACL injuries in military tactical athletes.

Finally, rescission of the ' 1994 Direct Ground Combat Definition and Assignment Rule' in January $2013^{8}$ fostered the integration of women into military occupations that were previously closed to them, such as combat arms. The Secretary of Defense issued a memorandum to direct all branches to execute their plans to fully implement women into all occupational specialties no later than 1 April 2016. ${ }^{9}$ Since this time, it is unclear how this policy has affected the incidence of ACL injury by sex within occupational specialties. Due to changes in force composition and operational requirements, an updated assessment of the factors associated with ACL injury risk in the tactical athlete is warranted. Therefore, the aim of this epidemiological retrospective cohort study was to evaluate the effects of military occupation, sex, rank and service branch on the risk of ACL injury in the US military from 2006 to 2018.

\section{METHODS}

A population-based epidemiological retrospective cohort study of all tactical athletes in the US Armed Forces was performed to assess the risk of sex, rank, service branch and military occupation on the incidence of ACL injury. The Defense Medical Epidemiological Database ((DMED), Defense Health Agency, Falls Church, Virginia, USA, https:/(bit.ly/DHADMEDv5) was used to identify relevant healthcare encounters. This database provides aggregated data for International Classification of Diseases (ICD)-9 and ICD-10 codes and de-identified patient characteristics, including sex, rank, categories of military occupations and service branch for all active and reserve tactical athletes. The database does not include any personal identifiable or personal health information and has been used previously for epidemiological study of lower extremity injury in the military. 11011

The database was queried for the number of distinct patients with a primary diagnosis of ACL injury (717.83 (old disruption of ACL), 844.2 (sprain of knee cruciate ligament), M23.61 (other spontaneous disruption of ACL) and S83.51 (sprain of ACL of knee)) on their initial encounter from 2006 to 2018. Individuals with repeat visits for the same diagnosis were only counted once in all analyses.

Cumulative incidence of ACL injury in male and female tactical athletes, enlisted members and officers, in each service branch (Army, Navy, Marine Corps and Air Force) and occupational category (enlisted specialties: special operations forces, mechanised/ armour, artillery/gunnery, aviation, engineers, maintenance, administration, intelligence and communication, logistics and maritime/ naval specialties; officer specialties: aviation, engineering and maintenance, administration, operations and intelligence, logistics and services) were calculated. Since military end strength fluctuates annually due to attrition and recruitment of replacements, ${ }^{12}$ the population at risk was a dynamic cohort. Incidence was calculated from the sum of ACL injuries and population at risk in the 13-year study epoch. Relative risk (RR) point estimates and 95\% CIs, risk difference, attributable risk (AR), number needed to harm $(\mathrm{NNH})$ and $\chi^{2}$ statistics were calculated to assess the effects of sex and military occupational category. The preceeding calculations were performed using Microsoft Excel for Mac 2016 (Microsoft, Redmond, Washington, USA).

A multivariable negative binomial regression was performed to evaluate time trends with respect to ACL injury incidence and included the factors of sex, rank and branch of service. Average marginal effects of predictor variables in the model were estimated for ease of interpretation. Due to overdispersion of the data indicated by the likelihood ratio test demonstrating that alpha is significantly different from zero, the negative binomial model was chosen over the Poisson regression model. ${ }^{13}$ The regression analysis was performed using Stata 16 software (StataCorp, College Station, Texas, USA).

Male tactical athletes were the reference group in the assessment of sex. Enlisted personnel served the reference group for rank due to the greater disease and non-battle injuries in this group compared with commissioned officers. ${ }^{14}$ Enlisted infantry and ground and naval gunfire officer groups were the reference in the assessment of occupational risk due to relatively higher physical requirements and organisational prioritisation of these occupational categories. ${ }^{11} 15$ Finally, the army was the reference group for service branch due to the population size and injury rates compared with the other services. ${ }^{16}$ The level of significance was $\mathrm{p}<0.05$ for all analyses, and no adjustments were made for multiplicity. RR point estimates were considered statistically significant if CIs did not cross 1.00 .

\section{RESULTS}

From 2006 to 2018, 59555 enlisted male officers sustained ACL injuries (4.8 per 1000 person-years) and 8350 enlisted female officers sustained ACL injuries (3.9 per 1000 person-years) for a total of 67905 enlisted member ACL injuries across the services (4.6 per 1000 person-years). During the same time period, 9983 male officers sustained ACL injuries (4.0 per 1000 person-years) and 2198 female officers sustained ACL injuries (4.5 per 1000 person-years) for a total of 12181 officer ACL injuries across the services (4.1 per 1000 person-years). Tables 1 and 2 display the counts and incidence of ACL injury. Online supplemental tables 1-4 detail the ACL injury counts, population at risk and injury rates in male and female enlisted members and officers.

ACL injury rates decreased over time during the study epoch (Figure 1). Male officer incidence decreased from 5.2 (95\% CI: 4.9 to 5.5 ) to 2.7 (95\% CI: 2.5 to 2.9) per 1000 person-years, female officer incidence decreased from 5.1 (95\% CI: 4.3 to 5.9 ) to 3.7 (95\% CI: 3.1 to 4.3 ) per 1000 person-years, enlisted male incidence decreased from 5.9 (95\% CI: 5.7 to 6.1) to 3.3 (95\% CI: 3.2 to $3.4)$ per 1000 person-years and enlisted female incidence decreased from 4.5 (95\% CI: 4.2 to 4.8 ) to 2.8 (95\% CI: 2.6 to 3.0) per 1000 person-years. Of note, the increase in incidence seen by female officers in the US Marines during 2010 and 2016 may potentially coincide with the changes in physical fitness standards for the Combat Fitness Test in the US Marine Corps. There is a plausible influence that the changes in standards may have resulted in overengagement in risk-taking activity to meet these standards.

Table 3 reports the risk of ACL injury by sex, with females referenced to males within their respective rank (officer vs enlisted) and occupation. The risk of ACL injury in female officers was 1.14 times that of their male colleagues (95\% CI: 1.09 to 1.19 ; AR: $12.0 \%$; $\mathrm{NNH}$ : $1836 ; \mathrm{p}<0.01)$ and was greater in aviation, administration and operations and intelligence occupations (RR: 1.16-1.39; AR: 14.0\%-28.1\%; NNH: 617-1650; p<0.05) compared with male officers. The risk of ACL injury in female enlisted members was 0.82 times that of their male colleagues (95\% CI: 0.80 to 0.83 ; AR: $-22.7 \%$; NNH: $-1134 ; \mathrm{p}<0.01)$ and was lower in maintenance, administration, intelligence and communication, logistics and maritime/naval specialties compared with male enlisted members (RR: $0.61-0.83$; AR: $-64 \%$ to $-20.9 \%$; NNH: -1173 to -523 ; $\mathrm{p}<0.01)$.

Results of the assessment of occupation on ACL injury risk are detailed in Table 4. Enlisted personnel in aviation, maintenance, administration, intelligence, communication and maritime/naval specialties had a $0.81-0.93$ lower risk compared with infantry 


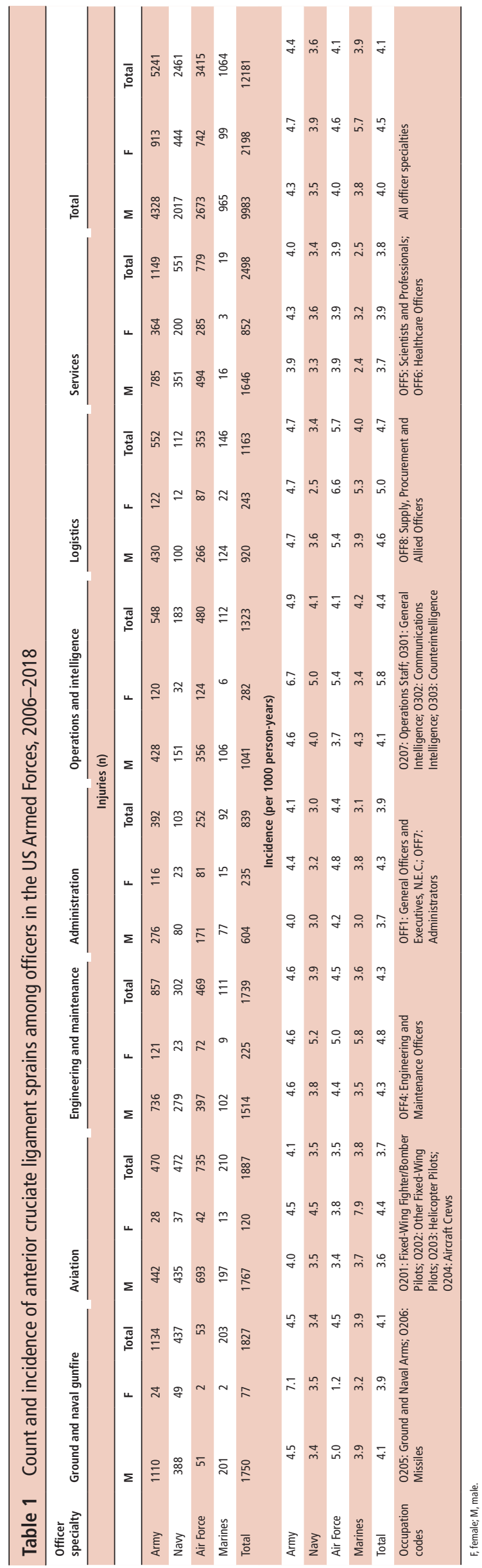

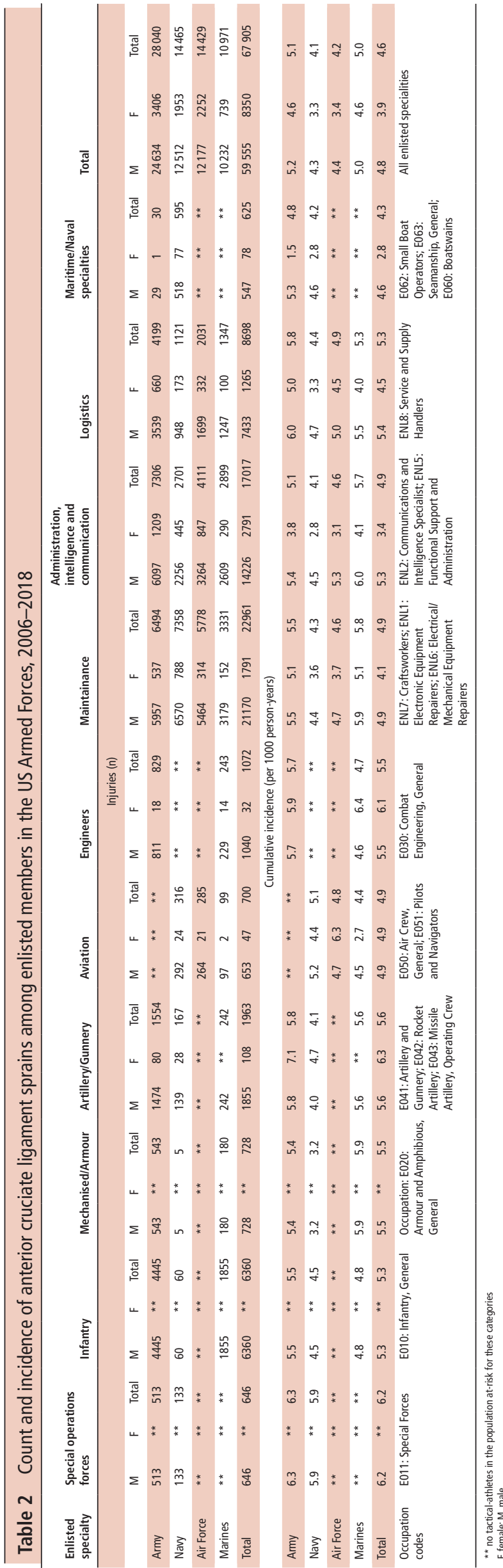




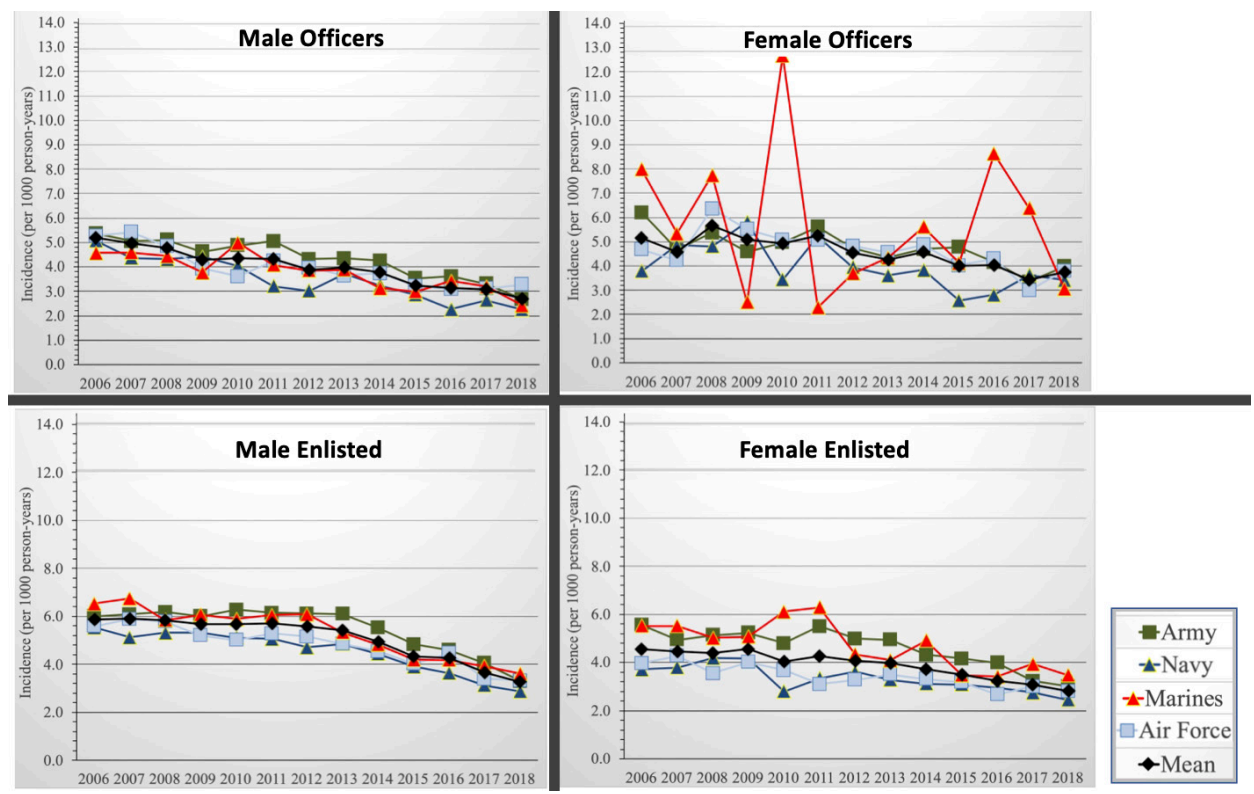

Figure 1 Anterior cruciate ligament injury incidence among male and female enlisted members and officers, US Armed Forces, 2006-2018.

(AR: $-23.5 \%$ to $-8.0 \%$; NH: -2576 to $-1002 ; \mathrm{p}<0.05$ ), and Special Operation Forces and Artillery/Gunnery occupations had a 1.07-1.19 greater risk compared with infantry (AR: 6.3\%-15.8\%; NNH: 1013-2827; $<<0.01)$. Aviation officers and services officers had a 0.89-0.92 lower risk of ACL injury compared with ground and naval gunfire officers (AR: $-12.9 \%$ to $-8.2 \%, \mathrm{NNH}:-2127$ to $-3187, \mathrm{p}<0.01$ ), and logistics officers had a 1.13 greater risk compared with ground and naval gunfire officers (AR: 11.8\%; NNH: $1808, \mathrm{p}<0.01)$.

The multivariable negative binomial regression demonstrated significant effects of time, sex, an interaction effect of sex with time, rank and branch of service on the incidence of ACL injury. Through calculation of the average marginal effect, the decrease in ACL injury incidence is 0.18 cases per 1000 person-years (95\% CI: 0.16 to 0.20 per 1000 person-years, $\mathrm{p}<0.01$ ), after averaging over the main and interactive effects of sex, rank and branch of service. This decrease is a $4.08 \%$ relative reduction in the injury rate per year $(95 \% \mathrm{CI}$ : $3.56 \%$ to $4.60 \%, \mathrm{p}<0.01)$. Officers had a 0.89 times lower rate of ACL injury (95\% CI: 0.86 to $0.93, \mathrm{p}<0.01)$ compared with enlisted personnel. The US Navy and US Air Force demonstrated 0.79 times (95\% CI: 0.75 to $0.84, \mathrm{p}<0.01)$ and 0.87 times $(95 \% \mathrm{CI}: 0.82$ to $0.91, \mathrm{p}<0.01$ ) the rate of the US Army, respectively, while the US Marine Corps was not statistically different compared with the US Army (0.96, 95\% CI: 0.91 to $1.02, \mathrm{p}=0.17)$.

Figure 2 depicts the interaction effect of time and sex on the outcome of ACL injury incidence. Through calculation of the average marginal effect for year, a significant difference was found in the rate of decrease between male and female officers $(\mathrm{p}<0.01)$. The decrease in incidence in male officers was greater compared with female officers, with the difference in the rate of decrease per year at 0.069 cases per 1000 person-years (95\% CI: 0.021 to 0.12 , $\mathrm{p}<0.01)$.

\section{DISCUSSION}

The primary finding of this study was the significant decrease in ACL injury rates over time regardless of sex, rank or branch of service, with injury rates declining at a steeper rate in male compared with female tactical athletes. The findings that ACL injury risk was modified by rank and occupation in male and female tactical athletes are the first to our knowledge to be reported.
Injury rates over time

The decrease in incidence of ACL injury likely represents a real trend with a potential contributing factor of changes in the operational tempo in the US Armed Forces over the study epoch. This could be plausibly explained by a decreased exposure to hazards with the decline of operational demands. The higher rates of ACL injury at the beginning of this study in 2006 represents a time of increased military operations with a high frequency of multiple deployements involved in OIF and OEF. Activity for these campaigns peaked in $2008,{ }^{17}$ and the campaigns concluded for OIF in 2011 and OEF in 2014. ${ }^{18}$ Changes in coding may explain a small portion of this change as the ICD-10 coding transition was mandated to occur in October 2015. However, the decline in ACL injury rates occurred prior to this timepoint. While there should be a direct mapping of the codes used in this study, it is unclear how injury data for this study may have been affected.

\section{Sex and rank}

Enlisted members, on average, had higher rates of ACL injury, but the risk of ACL injury by sex demonstrated an effect modification depending on rank. Female officers had a higher risk compared with male officers regardless of occupation. This was contrasted by enlisted females who demonstrated lower risk compared with enlisted males regardless of occupation. The prior population-based study by Owens et $a l^{1}$ did not stratify by rank, which potentially masked risk differences between male and female officers.

The relationship between sex and rank is noteworthy when compared with what is reported in the athlete population. Accounting for the relative numbers of male and female athletes, incidence of ACL injury is higher in female athletes. ${ }^{19}$ Furthermore, when highly active groups of tactical athletes were studied, higher incidence of ACL injury was reported in female tactical athletes. ${ }^{5}$ It was surprising that the relative risk of ACL injury was lower in female enlisted personnel compared with their male counterparts regardless of occupation for this younger group ${ }^{20}$ within the military. This finding, when considered with the injury reduction observed in officers, challenges the assumption that younger, physically active female officers are at higher risk for ACL injury. 


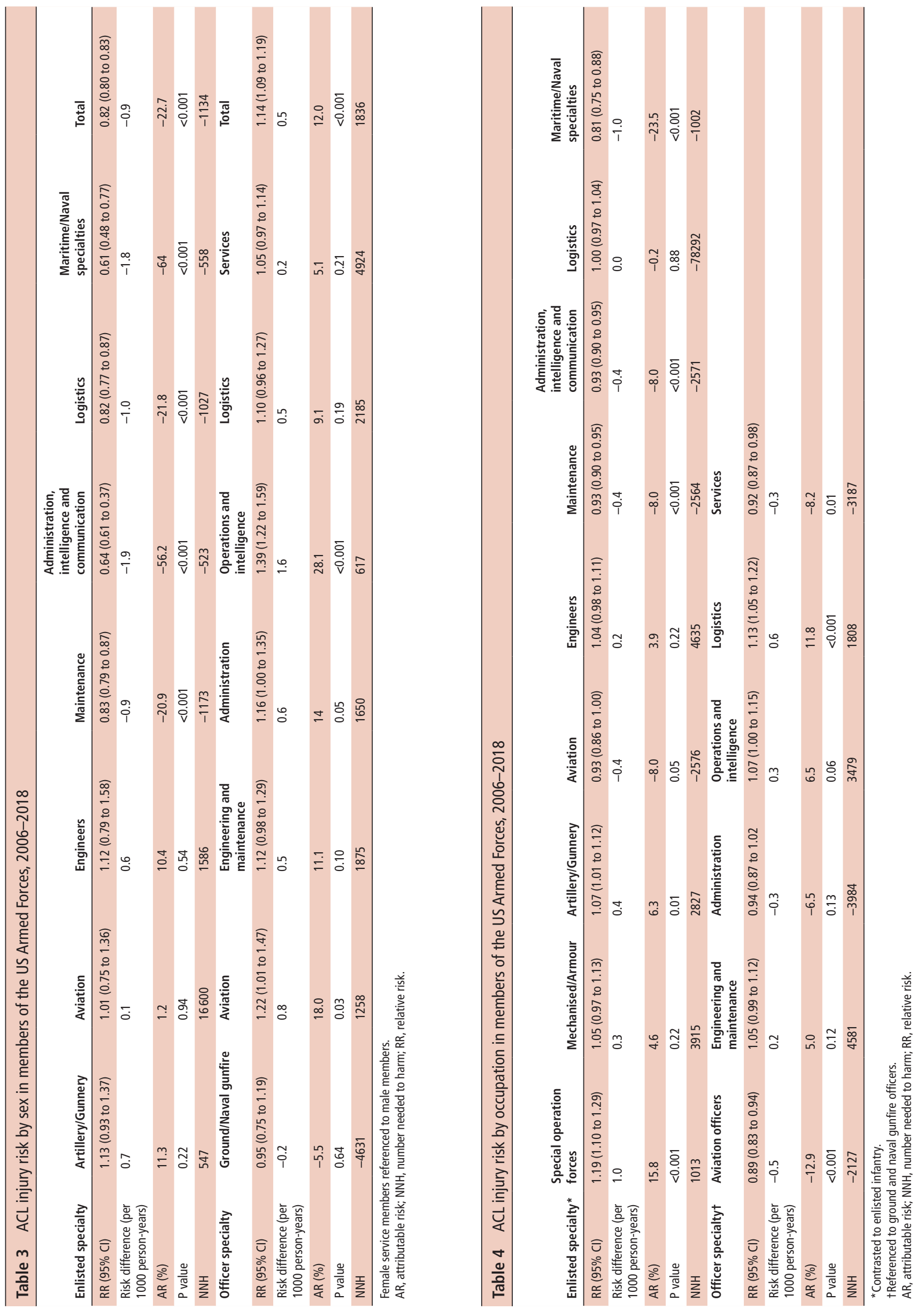




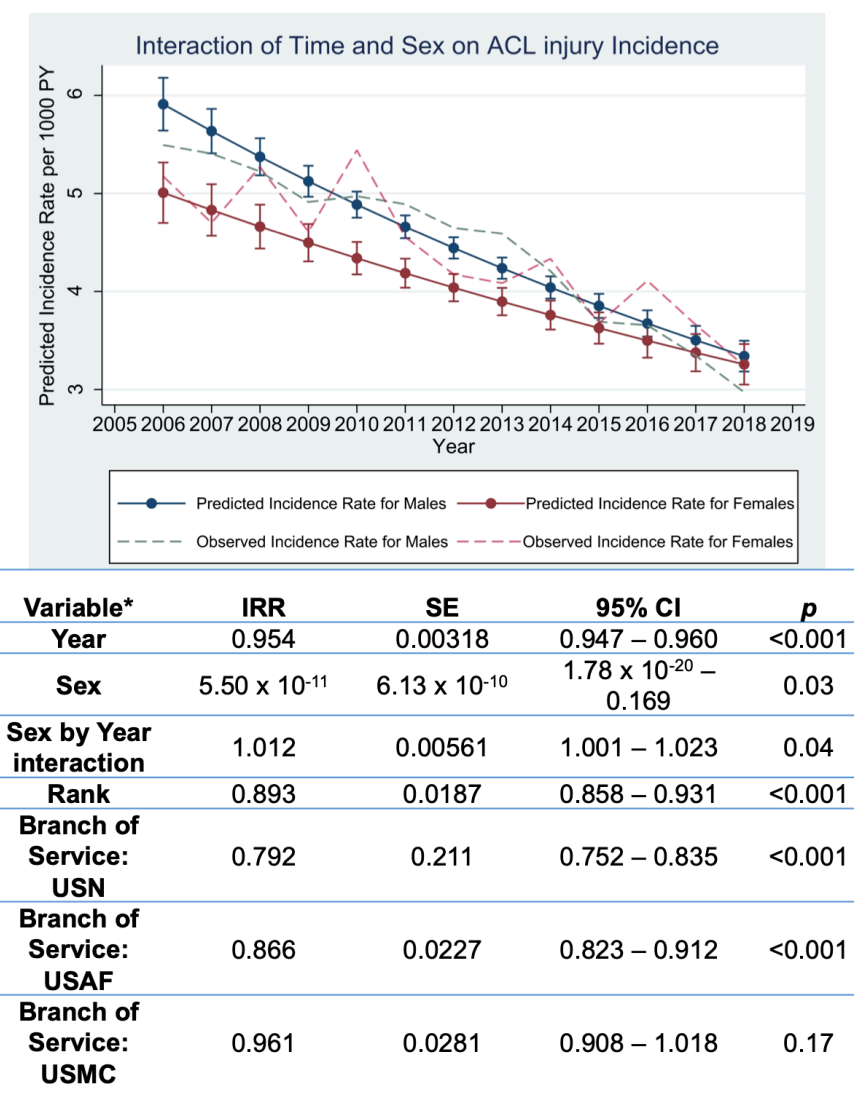

Figure 2 Negative binomial regression model for incident rate ratio (IRR) estimates of ACL injury over time, adjusted for sex, rank and branch of service, in members of the US Armed Forces, 2006-2018. USAF, United States Air Force; USMC, United States Marine Corps; USN, United States Navy; SE, standard error; $\mathrm{Cl}$, confidence interval.

One important difference between athletes and tactical athletes is that men and women train side by side in the US military, whereas competitive sports are stratified by sex. While tactical athletes are required to meet age-specific and sex-specific physical fitness testing standards, this is not the case regarding occupational requirements. As women increasingly enter into occupations that were previoulsy closed to them, it is plausible that the findings of sex, rank and military occupation will likely change. Finally, it is possible that young, enlisted males are participating in activities outside of their military occupation that are increasing the risk for ACL injury in this group compared with their female counterparts.

\section{Occupation and rank}

Among officers and enlisted, the risk of ACL injury varied depending on occupation. Exposures to hazards may contribute to the occupational differences observed. This study found that enlisted occupations where vehicles were primarily employed or were more sedentary in nature compared with infantry had lower risk of ACL injury. Aviation, maintenance, administration, intelligence, communication and maritime/naval specialties had significantly lower risk compared with infantry. Occupations where the knee is loaded on uneven surfaces are a known predisposing factor for ACL injury. ${ }^{21}$ Infantry members have higher exposure to hazards that can lead to ACL injury, such as rucking, manoeuvring and training over variable terrain. Similarly, aviation and services officers had a statistically lower risk of ACL injury compared with ground and naval gunfire officers.
Special Operations Forces and Artillery/Gunnery occupations were at a statistically higher risk of ACL injury compared with infantry. The highest risk of ACL injury by occupation found in this study was in the Special Operations Forces; this may be explained by the increased intensity and frequency of tactical training with a correspondingly high level of musculoskeletal injury that is known to occur in this community. ${ }^{22}$ Occupation-specific training and physical activity levels alone are likely not the only important factors driving ACL injury. Risk-taking behaviours that are culturally influenced and vary by occupational communities are likely contributing factors as well.

\section{Social determinants}

ACL injury is not typically self-limiting, and the billed medical encounters used to generate the data in this study are more likely to represent the true incidence. Due to the severity of an acute ACL injury, bias due to healthcare utilisation is not likely to have a large impact on the study results. However, even with ACL injury, barriers to seeking care by tactical athletes should be considered. Fear that future career opportunities may be negatively affected is a concern that may result in under-reporting of injuries. ${ }^{23}$ Additional reasons that may affect reporting include the service member's perception of the convenience and quality of medical care they will receive. ${ }^{24}$ The cultural environment of the military reinforces the desire to put aside pain associated with an injury to ensure that the mission is completed and to avoid the negative perceptions associated with injury. ${ }^{24}$ It is also plausible that under-reporting may disproportionately affect certain occupations more than others. ${ }^{25}$

\section{Clinical and research implications}

This study highlight important trends of ACL injury in regard to sex, occupation, rank, branch of service and changes over time. Specific hazards and exposures associated with military occupations should be explored in order to mitigate the risks. This is especially critical in communities such as Special Operations Forces, where a relatively smaller number of specialised tactical athletes must perform highly demanding physical tasks that are crucial to mission accomplishment. Surveillance of ACL injury should continue as the percentage of women in previously restricted combat roles grows. It is essential for policymakers to understand the salient factors associated with ACL injury in the military and within subpopulations, so appropriate prophylaxis and injury management can be planned. As rehabilitation specialists across the military continue to be incorporated into patient-centred medical homes and assigned to operational units, the effect on injury risk, rehabilitation and return to duty rates should be investigated.

\section{Strengths and limitations}

The DMED allows for a population-based analysis which provides the best estimation of ACL injury incidence to be captured based on billed medical encounters. This permitted the calculation of sex as a non-modifiable intrinsic factor and exploration of time, rank, branch of service and military occupation as factors for ACL injury. There are also important limitations associated with this study due to inherent constraints associated with DMED. While using initial encounters allowed for the calculation of incidence, this study is also limited in the ability to capture laterality of an injury, and a new injury on the contralateral side may not be counted as such. Salient factors associated with ACL injury that have been identified in tactical athletes are unable to be measured with this database, to include factors such as medical history or body mass index. Finally, a limitation of the diagnosis code 844.2 (sprain of knee cruciate ligament) is the inclusion of posterior cruciate ligament (PCL) injuries. 
However, PCL injuries are relatively scarce in comparison to ACL injuries and would likely only add minimal bias to the overall results of this study.

\section{CONCLUSION}

Sex, rank, branch of service and military occupation have been found to be risk factors for ACL injury. There was a statistically significant decrease in the incidence of ACL injuries among tactical athletes in the US Armed Forces between the years 2006 and 2018 at an average rate of 0.18 cases per 1000 person-years or a $4.08 \%$ relative reduction each year. The rate of decrease was higher in male tactical athletes when considering rank and branch of service. The relationship of ACL injury incidence and sex was modified by rank. It is plausible that the physical demands and opportunity for exposure within specific military occupations in the enlisted and officer communities may play a role in the differences in ACL injury incidence among occupations reported in this study. Despite the decline in incidence among tactical athletes in the US military over time, the rates of ACL injury still remain higher than the civilian population.

This work was presented at the 63rd Annual Meeting of the Society of Military Orthopaedic Surgeons in Olympic Valley, California, USA, December 2021. The preprint of this manuscript is archived on medRxiv at DOI: 10.1101/2021.09.30.21264383. This study was completed by Dr Aubrey Aguero in partial fulfilment of the academic requirements for the $\mathrm{PhD}$ in Rehabilitation Sciences at the University of Pittsburgh.

\section{Twitter J M Hart @JoeHartUVA and J J Fraser @NavyPT}

Contributors $A A D$ and $\mathrm{JJ}$ contributed to data analysis, interpretation and drafting this manuscript. AJM and JMH contributed to data interpretation. SDR contributed to data analysis. JJF contributed to study design, data analysis, interpretation, drafting, and is responsible for the overall content of this manuscript as the guarantor. All authors have reviewed and approved this manuscript.

Funding The authors have not declared a specific grant for this research from any funding agency in the public, commercial or not-for-profit sectors.

Disclaimer The views expressed in this article are those of the authors and do not necessarily reflect the official policy or position of the Department of the Navy, Department of Defence or the US Government. ADA, AJM and JJF are military service members or employees of the US Government. This work was prepared as part of their official duties. Title 17, U.S.C. §105 provides that copyright protection under this title is not available for any work of the US Government. Title 17, U.S.C. §101 defines a US Government work as work prepared by a military service member or employee of the US Government as part of that person's official duties.

Competing interests ADA, AJM and JJF are military service members or employees of the US Government. This work was prepared as part of their official duties.

\section{Patient consent for publication Not applicable.}

Ethics approval The study protocol was approved by the Naval Health Research Centre Institutional Review Board in compliance with all applicable Federal regulations governing the protection of human subjects. Research data were derived from an approved Naval Health Research Centre Institutional Review Board protocol number NHRC.2020.0203-NHSR.

Provenance and peer review Not commissioned; externally peer reviewed.

Data availability statement All data relevant to the study are included in the article or uploaded as supplementary information. Not applicable.

Supplemental material This content has been supplied by the author(s). It has not been vetted by BMJ Publishing Group Limited (BMJ) and may not have been peer-reviewed. Any opinions or recommendations discussed are solely those of the author(s) and are not endorsed by BMJ. BMJ disclaims all liability and responsibility arising from any reliance placed on the content. Where the content includes any translated material, BMJ does not warrant the accuracy and reliability of the translations (including but not limited to local regulations, clinical guidelines, terminology, drug names and drug dosages), and is not responsible for any error and/or omissions arising from translation and adaptation or otherwise.

Open access This is an open access article distributed in accordance with the Creative Commons Attribution Non Commercial (CC BY-NC 4.0) license, which permits others to distribute, remix, adapt, build upon this work non-commercially, and license their derivative works on different terms, provided the original work is properly cited, appropriate credit is given, any changes made indicated, and the use is non-commercial. See: http://creativecommons.org/licenses/by-nc/4.0/.

\section{ORCID iDs}

Aubrey D Aguero http://orcid.org/0000-0002-4217-6798

J J Irrgang http://orcid.org/0000-0002-7529-2672

A J MacGregor http://orcid.org/0000-0003-1020-7390

S D Rothenberger http://orcid.org/0000-0001-8300-5947

J M Hart http://orcid.org/0000-0002-0410-5112

J J Fraser http://orcid.org/0000-0001-9697-3795

\section{REFERENCES}

1 Owens BD, Mountcastle SB, Dunn WR, et al. Incidence of anterior cruciate ligament injury among active duty U.S. military servicemen and servicewomen. Mil Med 2007;172:90-1.

2 Belmont PJ, Goodman GP, Waterman B, et al. Disease and nonbattle injuries sustained by a U.S. Army Brigade combat team during operation Iraqi freedom. Mil Med 2010;175:469-76.

3 Moses B, Orchard J, Orchard J. Systematic review: annual incidence of ACL injury and surgery in various populations. Res Sports Med 2012;20:157-79.

4 Peterson SN, Call MH, Wood DE, et al. Injuries in naval special warfare Sea, air, and land personnel: epidemiology and surgical management. Oper Tech Sports Med 2005;13:131-5.

5 Gwinn DE, Wilckens JH, McDevitt ER, et al. The relative incidence of anterior cruciate ligament injury in men and women at the United States naval Academy. Am J Sports Med 2000;28:98-102.

6 Peebles LA, O'Brien LT, Dekker TJ, et al. The Warrior athlete part 2-Return to duty in the US military: advancing ACL rehabilitation in the tactical athlete. Sports Med Arthrosc 2019:27:e12-24.

7 Antosh IJ, Patzkowski JC, Racusin AW, et al. Return to military duty after anterior cruciate ligament reconstruction. Mil Med 2018;183:e83-9.

8 Dempsey ME, Panetta LE, the Eof. Direct ground combat definition and assignment rule. memorandum for secretaries of the military Departemtns, acting under Secretary of defense for personnel and readiness, and Chiefs of the military services. 2013. Washington, DC: Joint Chiefs of Staff, 1994.

9 Carter A. Implementation guidance for the full integration of women in the armed forces, 2015

10 Padua DA. Executing a collaborative prospective risk-factor study: findings, successes, and challenges. J Ath/ Train 2010;45:519-21.

11 Glaviano NR, Boling MC, Fraser JJ. Anterior knee pain risk differs between sex and occupation in military tactical athletes. J Ath/ Train 2021. doi:10.4085/1062-60500578.20. [Epub ahead of print: 31 Mar 2021].

12 Marrone JB. Predicting 36-month Attirtion in the U.S. military: a comparison across service branches. Rand Corporation, 2020

13 Cameron AC, Trivedi PK. Regression analysis of count data. Cambridge University Press, 1998.

14 Belmont PJ, Owens BD, Schoenfeld AJ. Musculoskeletal injuries in Iraq and Afghanistan: epidemiology and outcomes following a decade of war. J Am Acad Orthop Surg 2016:24:341-8

15 Anderson MK, Grier T, Canham-Chervak M, et al. Occupation and other risk factors fo injury among enlisted U.S. Army soldiers. Public Health 2015;129:531-8.

16 Jones BH, Canham-Chervak M, Canada S, et al. Medical surveillance of injuries in the U.S. military descriptive epidemiology and recommendations for improvement. Am J Prev Med 2010:38:S42-60.

17 Belasco A. Troop levels in the Afghan and Iraq wars FY2001-FY2012: cost and other potential issues. Congressional Research Service, 2009.

18 Torreon BS. U.S. periods of war and dates of recent conflicts. Congressional Research Service, 2019.

19 Arendt EA, Agel J, Dick R. Anterior cruciate ligament injury patterns among collegiate men and women. J Ath/ Train 1999:34:86-92.

202018 Demographics: Profile of the Military Community. Department of defense: office of the Deputy assistant Secretary of defense for military community and family policy, 2019.

21 Bliss JP. Anterior cruciate ligament injury, reconstruction, and the optimization of outcome. Indian J Orthop 2017:51:606-13.

22 Abt JP, Sell TC, Lovalekar MT, et al. Injury epidemiology of U.S. Army special operations forces. Mil Med 2014;179:1106-12.

23 Smith L, Westrick R, Sauers S, et al. Underreporting of musculoskeletal injuries in the US Army: findings from an infantry Brigade combat team survey study. Sports Health 2016;8:507-13.

24 Fraser JJ, Schmied E, Rosenthal MD, et al. Physical therapy as a force multiplier: population health perspectives to address short-term readiness and long-term health of military service members. Cardiopulm Phys Ther J 2020;31:22-8.

25 Cohen BS, Pacheco BM, Foulis SA, et al. Surveyed reasons for not seeking medical care regarding musculoskeletal injury symptoms in US army trainees. Mil Med 2019:184:e431-9. 